\title{
Skeletal Muscle Ventricles (SMVs) and Biomechanical Hearts (BMHs) with a Self-Endothelializing Titanized Blood Contacting Surface
}

\author{
Norbert W. Guldner, Peter Klapproth, \\ Hangörg Zimmermann and Hans- H. Sievers \\ Additional information is available at the end of the chapter \\ http://dx.doi.org/10.5772/55993
}

\section{Introduction}

For most patients with end-stage heart failure (more than 90\%) there is no definitive treatment option up to now. This fact is caused on the one hand by a severe shortage in donor hearts, and on the other hand by technical and economic limitations of mechanical cardiac assist devices and artificial hearts. An additional cardiac output of 2-3 litres per minute should give most patients with end-stage heart failure a better quality of life and a longer survival. Latissimus dorsi muscle as a source for muscular blood pumps would have several advantages. Its availability is nearly unlimited, there is no foreign tissue rejection and of course no need for an immune-suppression, less risk of infection and this procedure should be less costly than heart transplantation and the treatment with fully implantable cardiac assist devices and artificial hearts.

Skeletal muscle ventricles (SMVs) and Biomechanical Hearts (BMHs) are experimental muscular blood pumps to support the circulation. They are developed and tested as future treatment option for patients with end stage heart failure. SMVs and BMHs basically have two main limitations: firstly muscle damage after electrical muscle fiber transformation from a fast twitched into a slow twitched non-fatigue muscle and secondly thromboembolic complications from the blood contacting surface especially when a muscular blood pump works on demand. Former investigators developed sack-ventricles within circulation in dogs pumping up to 4 years [1-5]. 


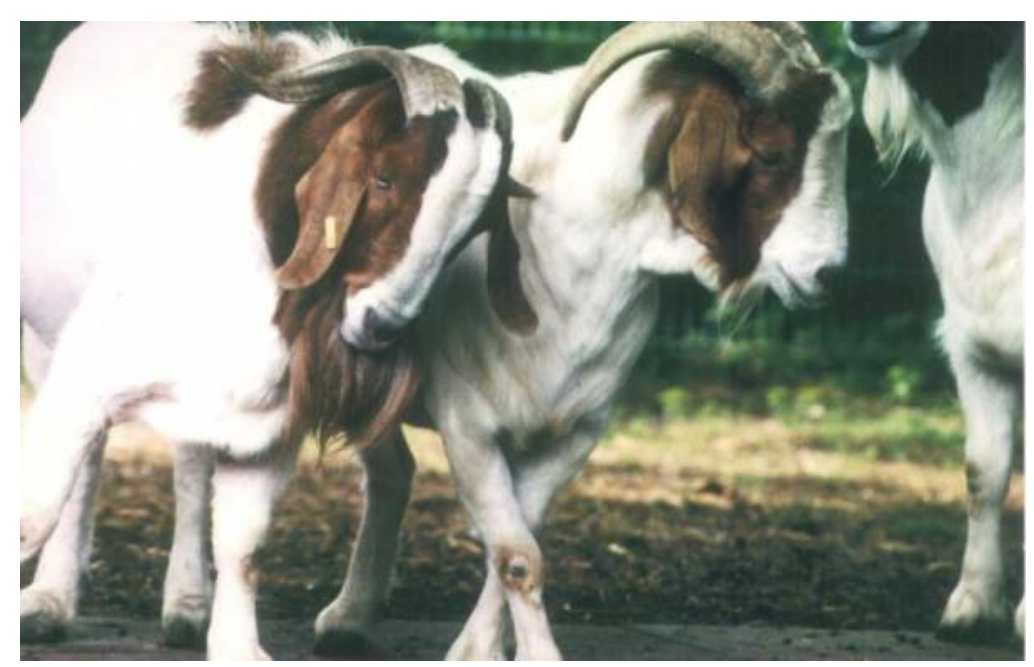

Figure 1. Boer goats with a weight between 60 and $100 \mathrm{~kg}$ and a latissimus dorsi muscle of 300 to $450 \mathrm{~g}$.
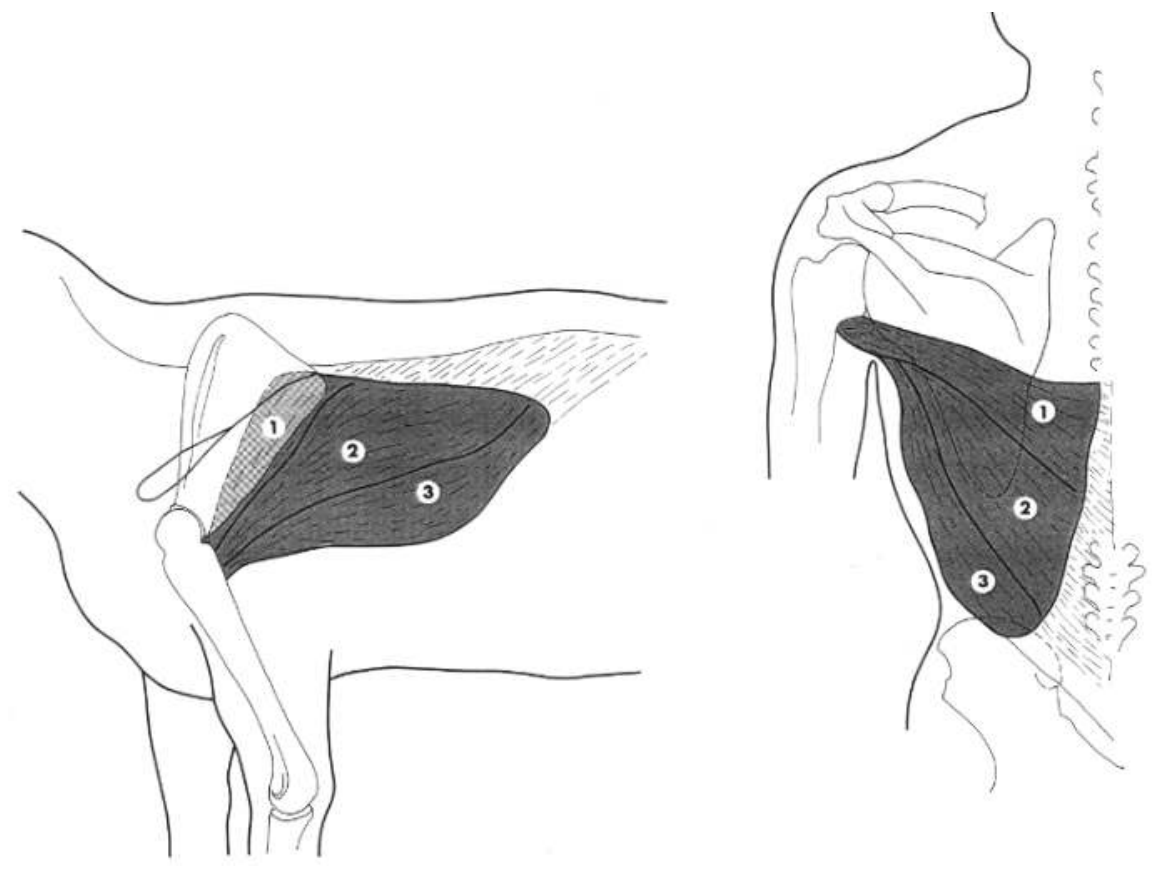

Figure 2. Topography of the latissimus dorsi muscle (LDM) in a big animal (goat) and a human. LDM consists of three parts: Pars transversalis (1), Pars obliqua (2) and Pars lateralis (3), LDMs weight is 300 to $450 \mathrm{~g}$ in Boer bocks and about $600 \mathrm{~g}$ in humans. 


\section{Training device}

To study muscle protection of LDM under different stimulation patterns and drugs to improve muscular power an elastic training device was created, where the LDM was wrapped around and muscle performance could become evaluated [6].

The training device (Figure 3) is made of silicone rubber (Q3, Dow Corning). It consists of a central chamber and two compliant side bladders filled with saline solution. The barrel-shaped central chamber and the side bladders have volumes of $150 \mathrm{~mL}$ and $50 \mathrm{~mL}$ each, respectively. The side bladders are constructed with a compliance of 1.0 to $1.3 \mathrm{~mL} / \mathrm{mmHg}$, simulating the windkessel characteristics of the arterial system in normal subjects with $1.07 \mathrm{~mL} / \mathrm{mmHg}$. More technical details can be found elsewhere (Guldner et al.,1994; 2000).

\section{Elastic Training Device}

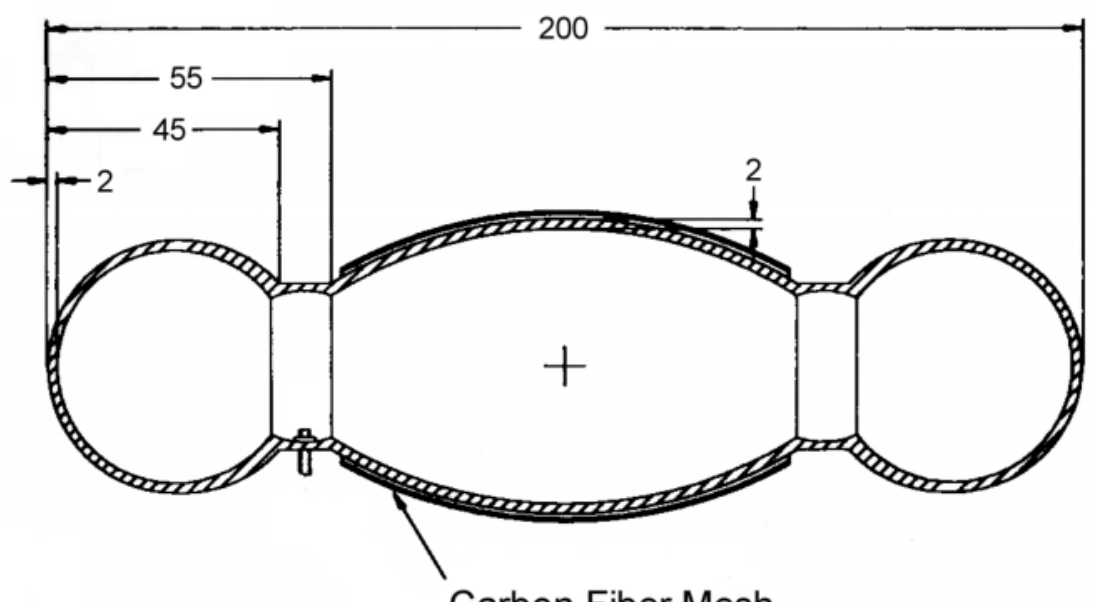

Figure 3. The Frog, an elastic training device, made of silicone, consists of a central pumping chamber which is compressible but not extendible (carbon fibre mesh).

\section{Intra-thoracic implantation}

Experiments were carried out in adult Boer goats (Figure 1), with a weight of $70 \pm 11 \mathrm{~kg}$. They were castrated 4 weeks before the operation to keep them together and avoid injuries between them. The experiments were performed in accordance with the Guide for the Care and Use of Laboratory Animals published by the National Institutes of Health. They were supervised by a representative of the District President of the local society for Prevention of Cruelty to Animals. 
The operation was performed under general anaesthesia. Left LDM was dissected free, folded to a double layer, and wrapped around the central chamber of the training device. The SMV was transferred into the thorax and fixed at the thoracic wall.

Commercially available myostimulators were used (Medtronic model 7420/7424 and Telectronics model 7220). An epi-mysial electrode 30mm long (custom-made, Medtronics, Bakken Research Center) was attached to the muscle close to the branches of the nervus thoracodorsalis. On the opposite side of the muscle, an electrode 60mm long (Medtronics SP 5591 - 500-60NMS) was placed sub-fascially.

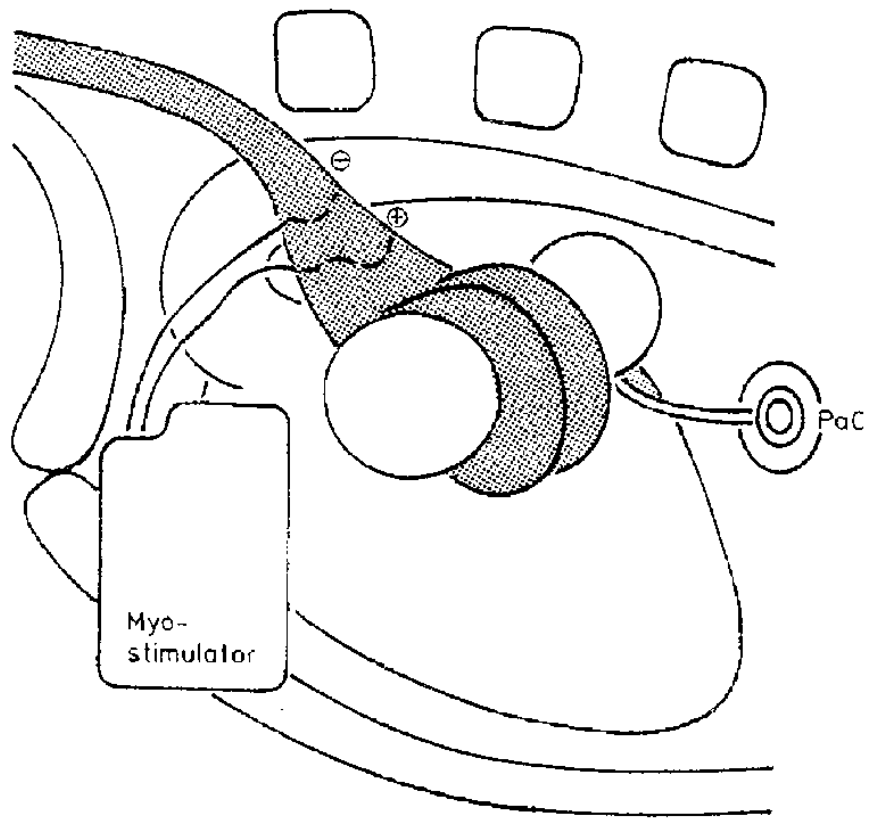

Figure 4. An intra-thoracic skeletal muscle ventricle is wrapped around the Frog: A myostimulator induces muscle contractions via 2 electrodes. Contractions of LDM cause a volume shift from the central chamber into the expanding bladders, with a corresponding pressure increase. This pressure is measured by piercing a subcutaneous vascular access port ( $\mathrm{PaC})$. 


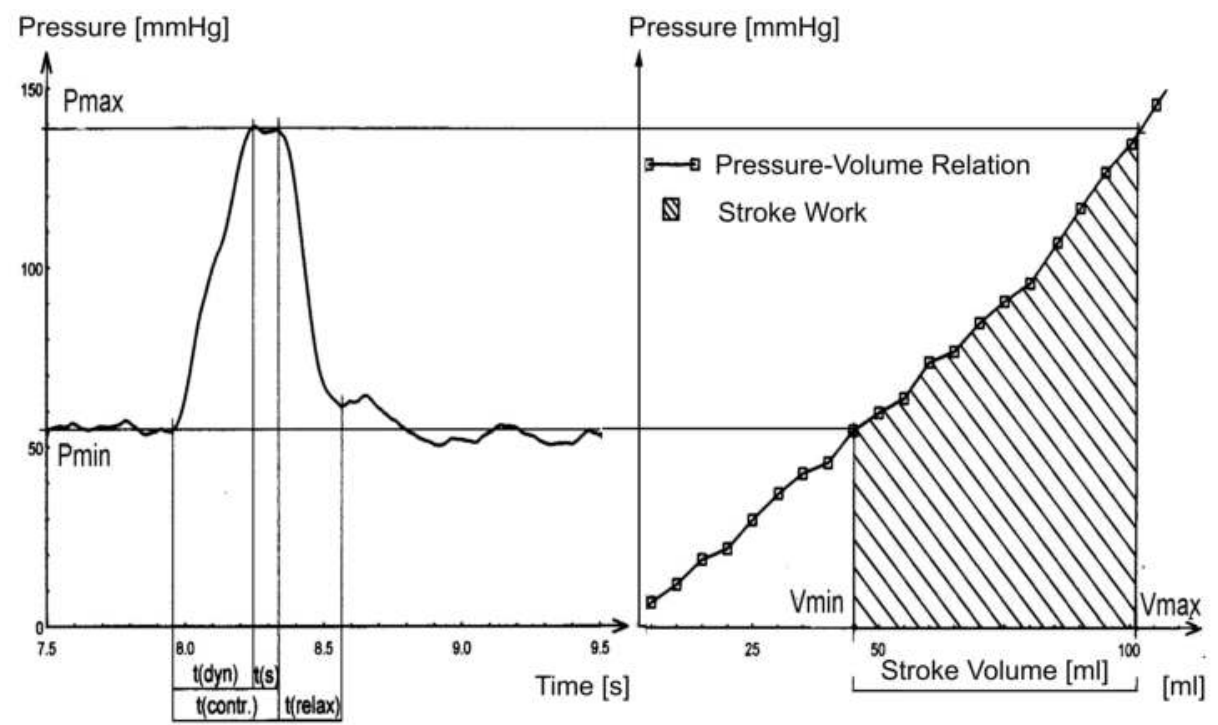

Figure 5. Method of stroke volume and stroke energy determination, relating pressure increase of a ventricle contraction (left) to the compliance curve of the bladders of the Frog, stroke volume is received (right). The area of the stroke volume below the compliance curve represents the stroke work or stroke energy [7].

Stroke volume evaluation is performed relating maximal pressure $\mathrm{P}_{\max }$ from the pressure curve during muscle contraction to the compliance curve of the Frog's elastic side bladders (Figure 5). Stroke volume multiplied with $P_{\max }$ results in stroke work $W$. Daily energy in $\mathrm{KJ} / \mathrm{d}$ is to calculate by stroke work W multiplied with the number of SMV contractions per day.

\section{Clenbuterol supported dynamic training of skeletal muscle ventricles against systemic load}

The profound loss of power that occurs in skeletal muscle after electrical conditioning has been the major limiting factor in its clinical application. This study investigates a 3-fold approach for chronic conditioning of skeletal muscle ventricles combining electrical transformation, dynamic training against systemic load and pharmacological support with clenbuterol.

In 10 adult male goats, SMVs were constructed from latissimus dorsi wrapped around an intrathoracic training device with windkessel characteristics [8]. SMVs were stimulated electrically and trained dynamically by shifting volume against systemic load. Group 1 goats

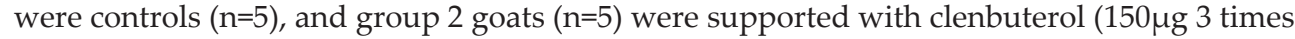
a week).

Peak pressure, stroke volume and stroke work per day were significantly improved $(p<0.007)$ in the clebuterol- treated group after $151 \pm 2.7$ days (Fig. 6). At termination, myosin heavy chains 
were totally transformed into myosin heavy chain-I in all SMVs. Other investigators found different functional and histological effects of clenbuterol in dogs [9].

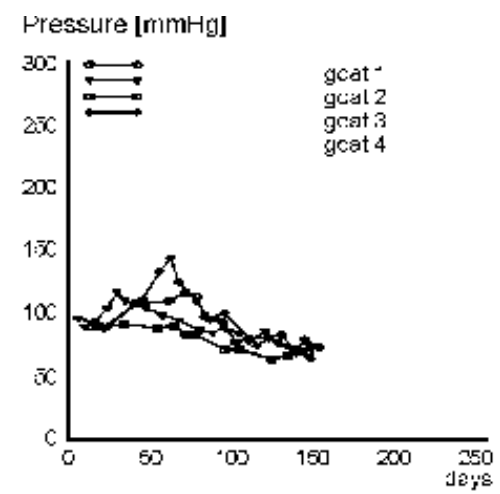

Volure [ml]
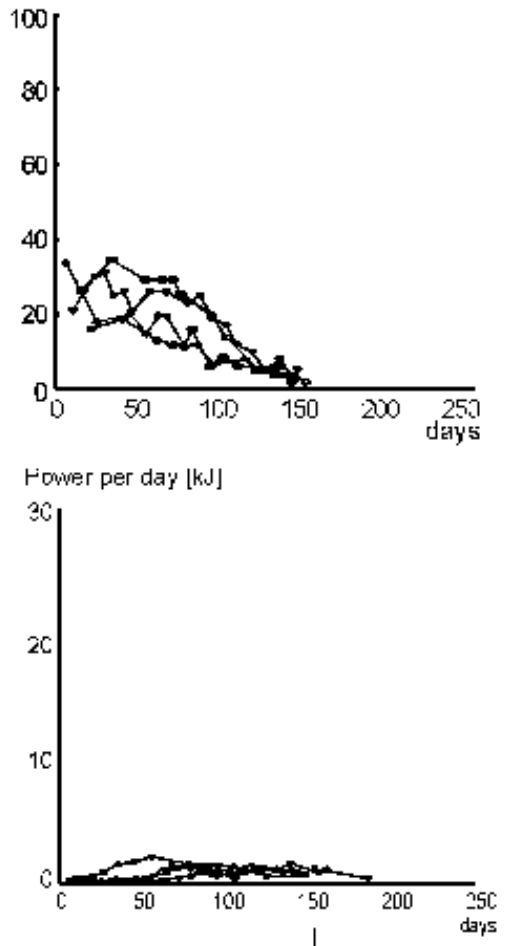

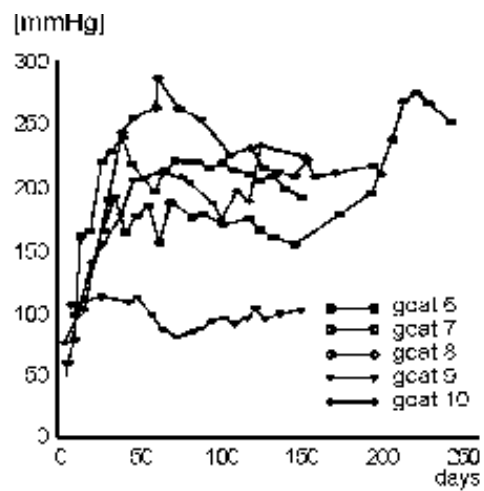

[ml]
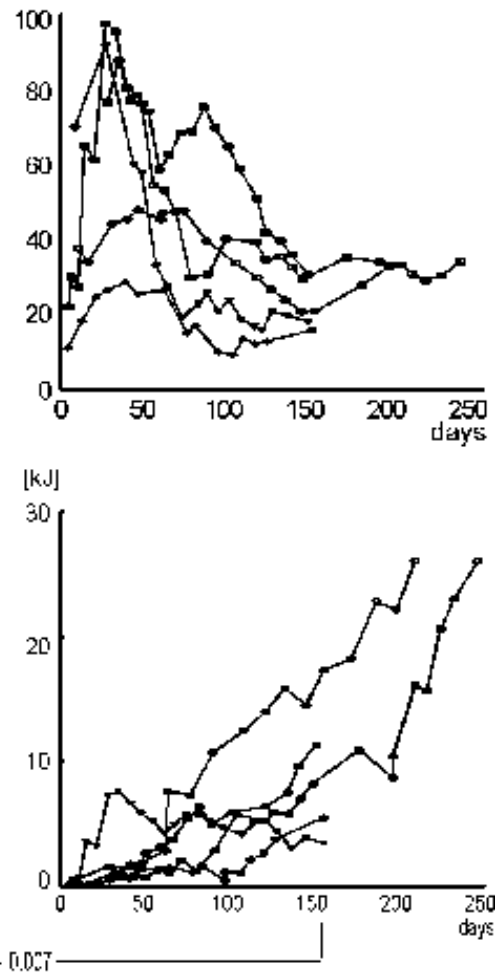

Figure 6. Time course of systolic pressure (top), stroke volume (middle), and power per day ( bottom) during dynamic training of SMVs without Clenbuterol $n=5$ (left) and supported by clenbuterol $n=5$ (right) against load conditions of 60 to $70 \mathrm{~mm} \mathrm{Hg}[8]$. 


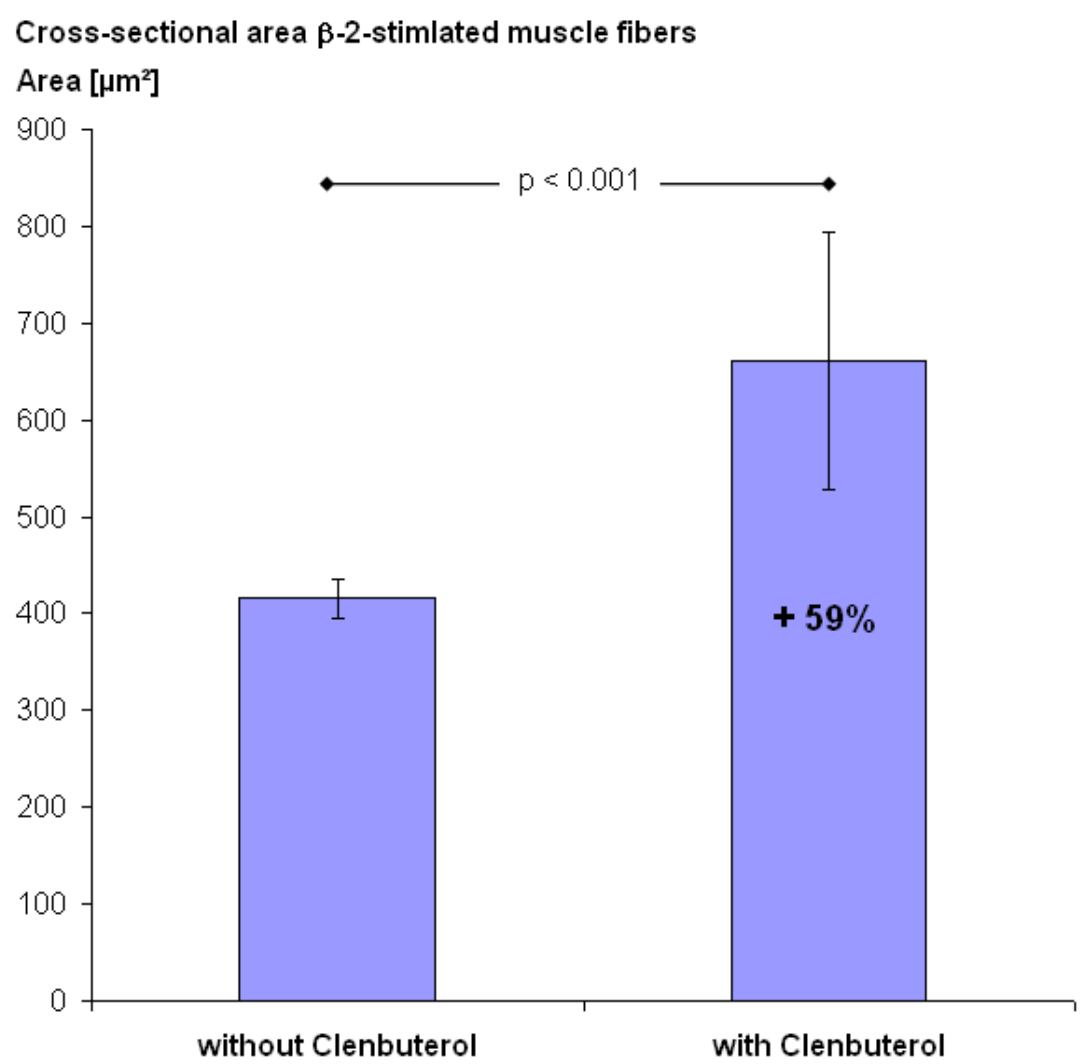

Figure 7. Cross-section areas of clenbuterol treated ( $\beta$-2-stimulated) muscle fibers were enhanced by $59 \%$.

\section{Fibertransformation preserving non-fatiguable Typ IIa fibers}

In our experience muscular blood pumps that were active over several months, were highly vulnerable when totally transformed into type I muscle showing severe muscle damage and decreased function. Thus, in our new experimental setting, encouraged by the Liverpool findings of the working group of Salmons and Jarvis [10], fast and fatigue resistant muscle ventricles were performed around the Frog. Pre-stimulation with about $2 \mathrm{~Hz}$ proceeded in 
situ, to open intramuscular collaterals connecting the proximal with the distal blood supply of the muscle and to increase capillary density. Thereafter we used continuous basic burst stimulation with an average pulses frequency of less than $1 \mathrm{~Hz}$. Intermittent series of pumping within the Frog were performed, measuring pumping capacity in correlation to stimulation frequency. This procedure should be a "model setting" for a pumping on demand. During our first investigations, we could see that intermittent pumping capacity was already manifold after 4 to 5 months of pumping (Figure 8).

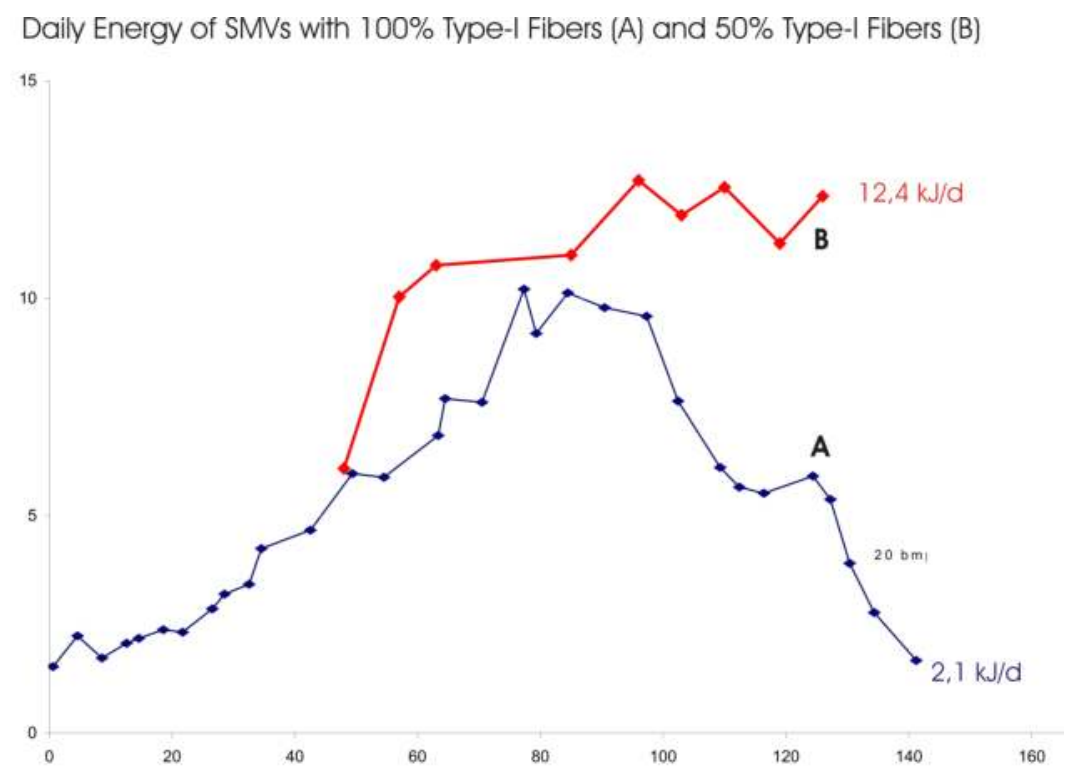

Figure 8. Daily energy of goat A (lower curve) with a mean pulse frequency of $5 \mathrm{~Hz}$, which is massively declined. With $1 \mathrm{~Hz}$ stimulation in goat B however (upper curve) a high pumping capacity was observed.

Mean electrical pulse frequency with $5 \mathrm{~Hz}$ of group A ( $\mathrm{n}=6)$ in Fig.9 resulted in a non relevant delivery of daily energy after 200 days of pumping. A $1 \mathrm{~Hz}$ stimulation of group B however showed an enhancing pressure and stroke volume and an increasing development of daily energy after 200 days with a well preserved muscular tissue.

Gel electrophoresis for myosin heavy chains MHC I and MHC IIa analysis (Figure 10) of group A with a mean pulse frequency of $5 \mathrm{~Hz}$ showed a composition of $\mathrm{MHC}$ I (bottom of the gel) and MHC IIa (top of the gel) with mainly MHC IIa in the controls (C). In the trained SMVs (T) of group A was 100\% MHC-I in all cases. In group B and with $1 \mathrm{~Hz}$ stimulation over months MHCIIa was preserved (50\% MHC-IIa and 50\% MHC-I). The preservation of Type II MHC in group B explains the more powerful contractions and the maintained pressure, stroke volume and daily energy (Figure 9). 


\section{Functional analysis of SMVs over more than 6 months of electrical stimulation}

Group A: $5 \mathrm{~Hz} n=6$

Pressure $[\mathrm{mmHg}]$
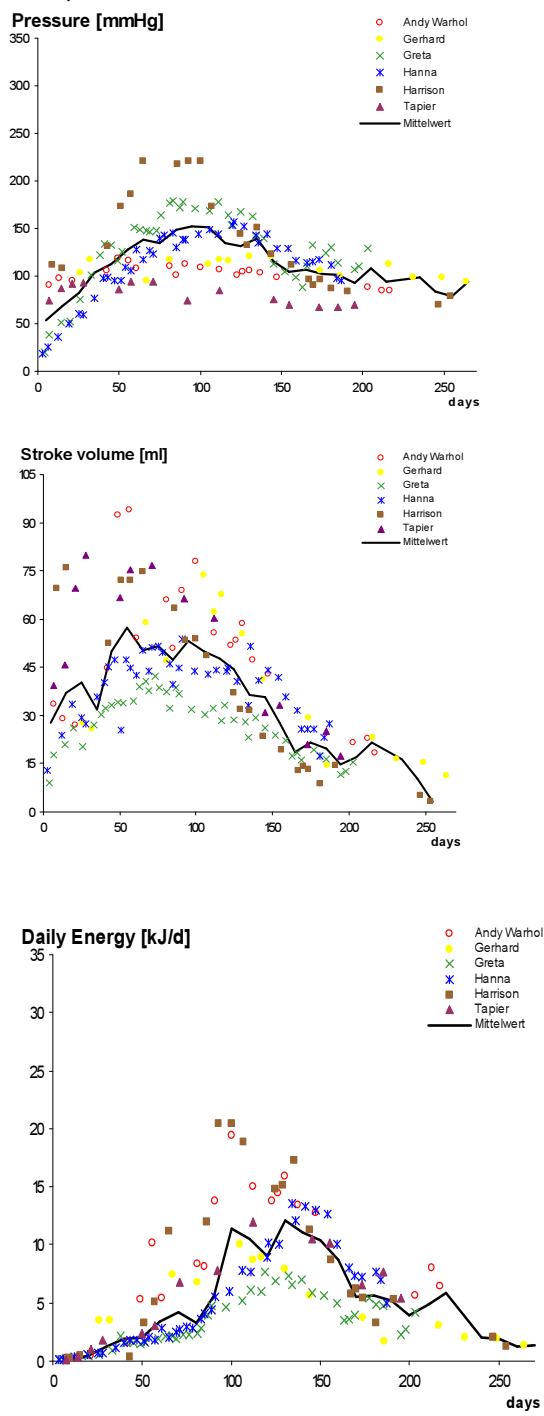

\section{Group B: $1 \mathrm{~Hz} \mathrm{n=6}$ \\ $[\mathrm{mmHg}]$}
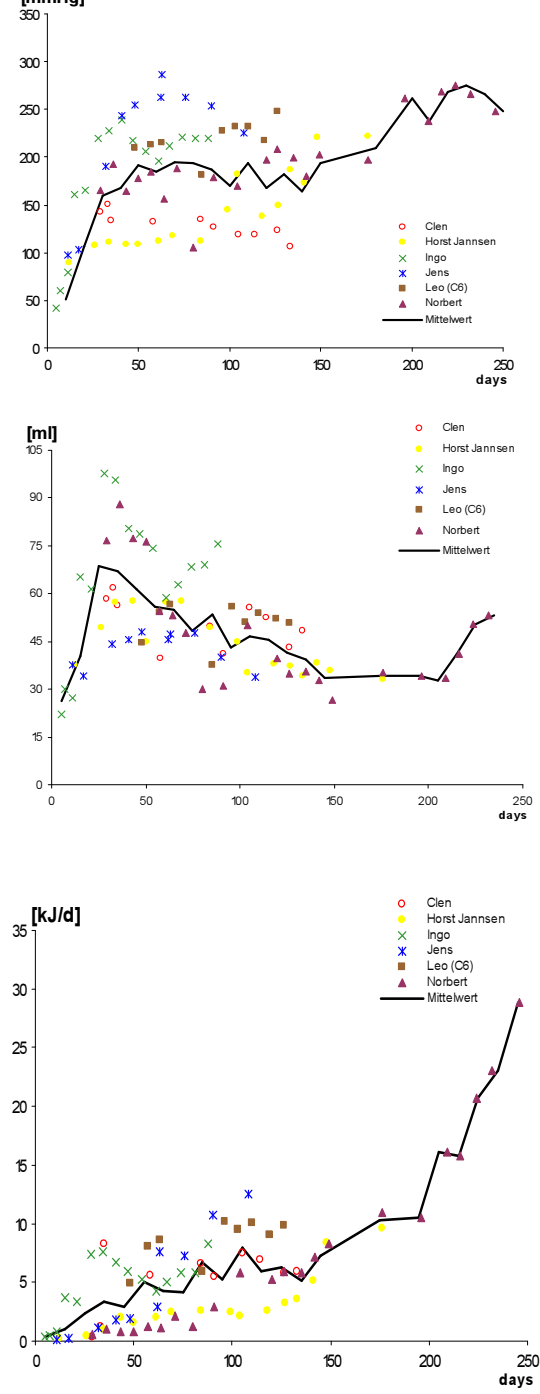

Figure 9. Systolic pressure (top), stroke volume (middle) and daily energy (bottom) of group A ( $\mathrm{n}=6)$ with a mean pulse frequency of $5 \mathrm{~Hz}$ (left) and with $1 \mathrm{~Hz}$ in group $B$ ( $n=6$, right). 


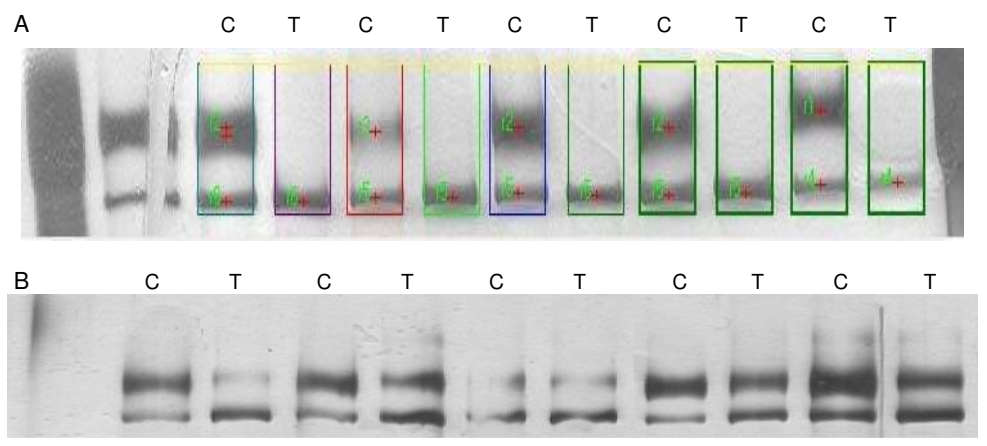

Figure 10. Gel electrophoresis of myosin heavy chains $\mathrm{MHC}$ I and $\mathrm{MHC}$ Ila from group A with a mean pulse frequency of $5 \mathrm{~Hz}$. Control (C) was the non stimulated contra-lateral LDM. In group B with a mean stimulation frequency of $1 \mathrm{~Hz}$, type Ila MHC is well preserved and about $50 \%$ after several months in all stimulated SMVs.

\section{Stroke volume of SMVs with $100 \%$ type-I-fiber (A) vs. SMVs with $50 \%$ type-IIa fiber (B)}

As an example one fast, relatively fatigue resistant SMV delivered a maximal pump volume of about $3 \mathrm{~L} / \mathrm{min}$. It could be maintained over two minutes. Thereafter it decreased to $1,5 \mathrm{~L} / \mathrm{min}$ after 5 minutes. This dynamic adaptation of stroke volume per minute in that high level of pumping volume up to $3 \mathrm{~L} / \mathrm{min}$ was solely possible in the $50 \%$ type IIa fibre muscle. $100 \%$ type I fibre ventricles did enhance its pumping capacity however only up to $1 \mathrm{~L} / \mathrm{min}$.

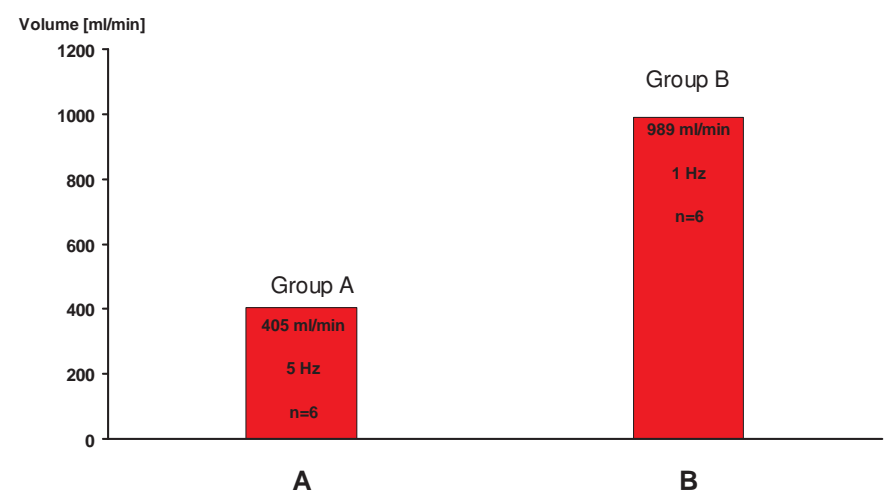

Figure 11. Stroke volumes evaluated in a Frog surrounded by a goat's SMV of a latissimus dorsi muscle of $330 \mathrm{~g}$ up to 200 days postoperatively. In group A with 100\% type I fibres stroke volume per minute was at $405 \mathrm{ml}$ and in the fast, relatively fatigue resistant muscle with about $50 \%$ type lla fibres stroke volume per minute was at 888 ml per minute. This amount of stroke volume per minute could be maintained over months. 


\section{Stroke Volume on Demand [m $1 / \mathrm{min}]$}

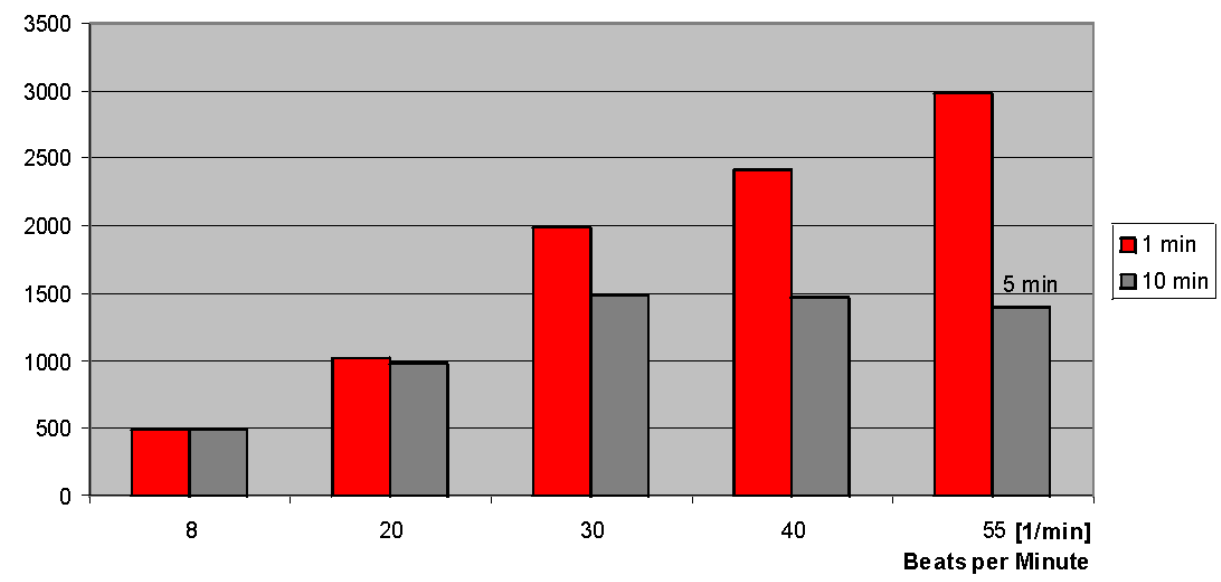

Figure 12. Stroke volumes of an "on demand" setting (see text!) evaluated in a Frog surrounded by a goat's SMV of a latissimus dorsi muscle of $330 \mathrm{~g} 6$ weeks postoperatively.

These recent experimental results in SMVs around the Frog were basic to construct a preclinical Biomechanical Heart Model on demand, which is described as follows.

\section{Valve-less Biomechanical Hearts}

Biomechanical Hearts, constructed in adult Boer goats $(\mathrm{n}=5)$, are blood pumps, consisting of a pumping chamber with clinically relevant stroke volumes [11]. They can be integrated into the circulation in a one-step operative procedure during pharmacological stimulation with the $\beta$-2-stimulator Clenbuterol (5 x150 $\mu \mathrm{g} / \mathrm{wk}$ ). This experimental pumping chamber, made of PTFE, was anastomosed to the descending aorta by two ring armoured PTFE-prostheses (Impra Medica GmbH, München), as shown in Figure 13. The pumping chamber was used mainly for three reasons: firstly, to stabilize the ventricular pump cavity with improved flow characteristics to minimize thrombo-embolic complications; secondly, to prevent muscle damage by overstretch-induced ischemia; and thirdly, to prevent a ventricular chamber rupture.

During surgery, the mean stroke volume of BMHs was 53.8 $\pm 22.4 \mathrm{ml}$. One month after surgery, in peripheral pressure, the mean and minimal diastolic pressure of BMH-supported heart cycle differed significantly from unsupported ones (Figure 14). After BMHsupported heart contractions, the subsequent maximal rate of pressure generation, $\mathrm{dP} / \mathrm{dt}$ $\max$ increased by $20.5 \pm 8.1 \%(\mathrm{p}<0.02)$. One $\mathrm{BMH}$, catheterized 132 days after surgery, shifted a volume of $34.8 \mathrm{~mL}$ per beat and $1.4 \mathrm{~L} / \mathrm{min}$ with a latissimus dorsi muscle of $330 \mathrm{~g}$ (Figure 14 , top). 


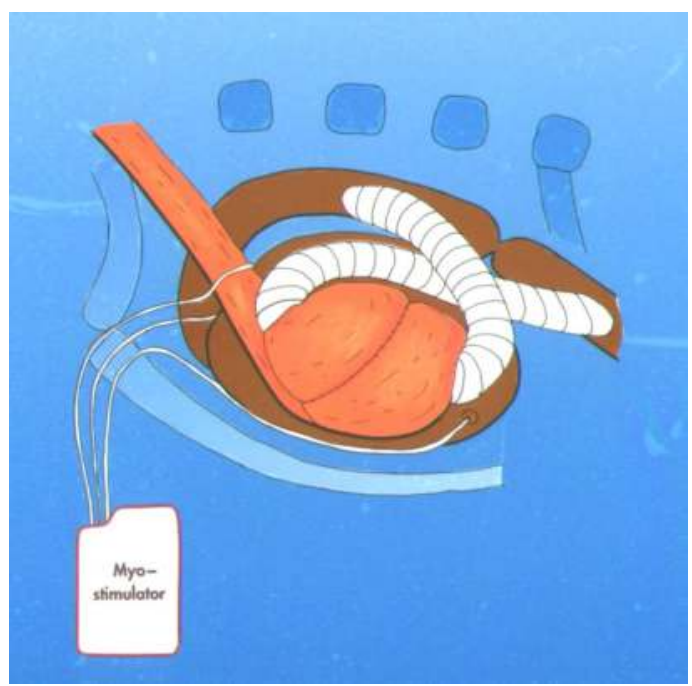

Figure 13. Scheme of an experimental setting in a big animal model in an aorto-aortic configuration. The thoracic aorta is ligated between the two anastomoses. Two muscular stimulation electrodes activate the LDM and an epicardial sensing electrode enables the syncronization with the heart cycle.
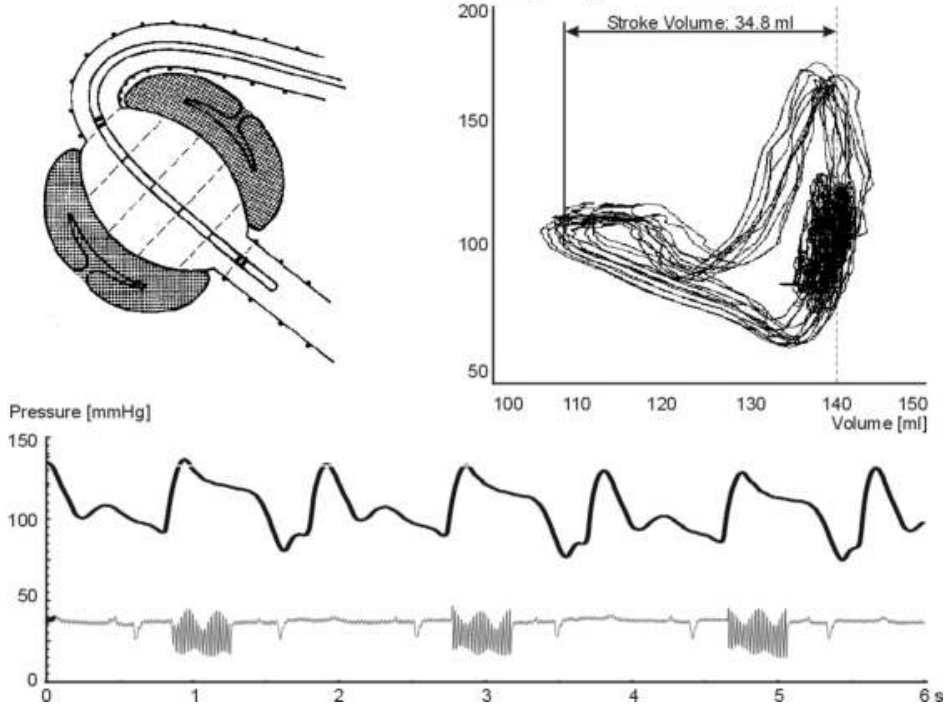

Figure 14. Stroke volume determination with a conductance catheter, placed within the pumping chamber of the $\mathrm{BMH}$ (left, top). Pressure-volume-loop of a BMH on postoperative day 132 with a stroke volume of $34.8 \mathrm{ml}$ and an output of $1400 \mathrm{ml}$ per minute (right, top). ECG with stimulation bursts, a pressure trace from a peripheral artery where the $\mathrm{BMH}$ is in a 1:2 mode and synchronized with the heart (bottom). 


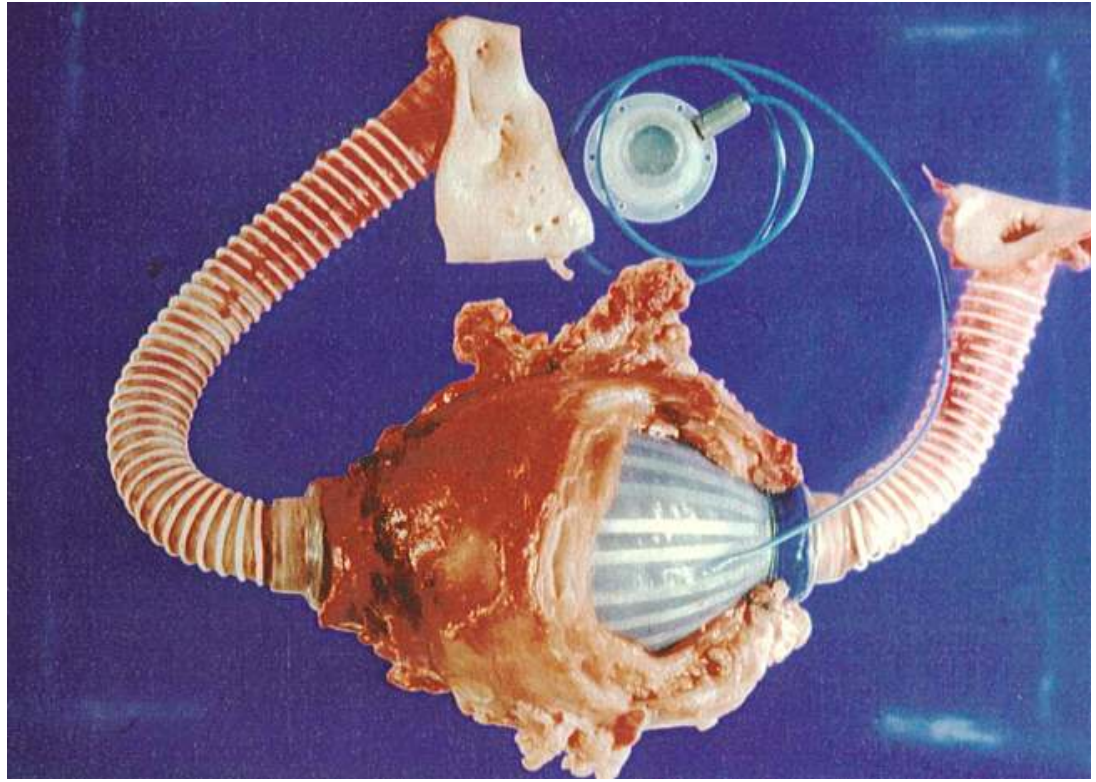

Figure 15. Explanted $\mathrm{BMH}$ without valves after 414 days of pumping within a Boer goat. The pumping chamber was made of a double layered polyurethane membrane including steel springs and it was connected to the aorta by ring armoured PTFE prostheses.

\section{Hemodynamic evaluations of a valve equipped Biomechanic Heart Model supporting a failing myocardium in goats}

As shown previously in goats, valve-less Biomechanical Hearts (BMHs) of a clinically relevant size could be trained effectively in the systemic circulation under support of clenbuterol. Pumping capacity was more than $1 \mathrm{~L} / \mathrm{min}$ but due to a high pendulum volume no significant flow contribution for the circulation was gained. Thus, the following investigations were performed to evaluate the efficacy of valve-equipped BMHs in comparison to valve-less BMHs. To mimic the clinical situation, this test was performed in failing hearts [12].

Heart failure was induced in adult Boer goats $(n=5)$ by a repeated intra-coronary embolization. A valve-bearing and balloon-equipped pumping chamber was integrated into the descending aorta simulating standardized circulatory BMH support. Circulatory flow was evaluated by a flow meter around the pulmonary artery. Myocardial function was evaluated by a conductance catheter placed in the left heart ventricle (Figure 16). 


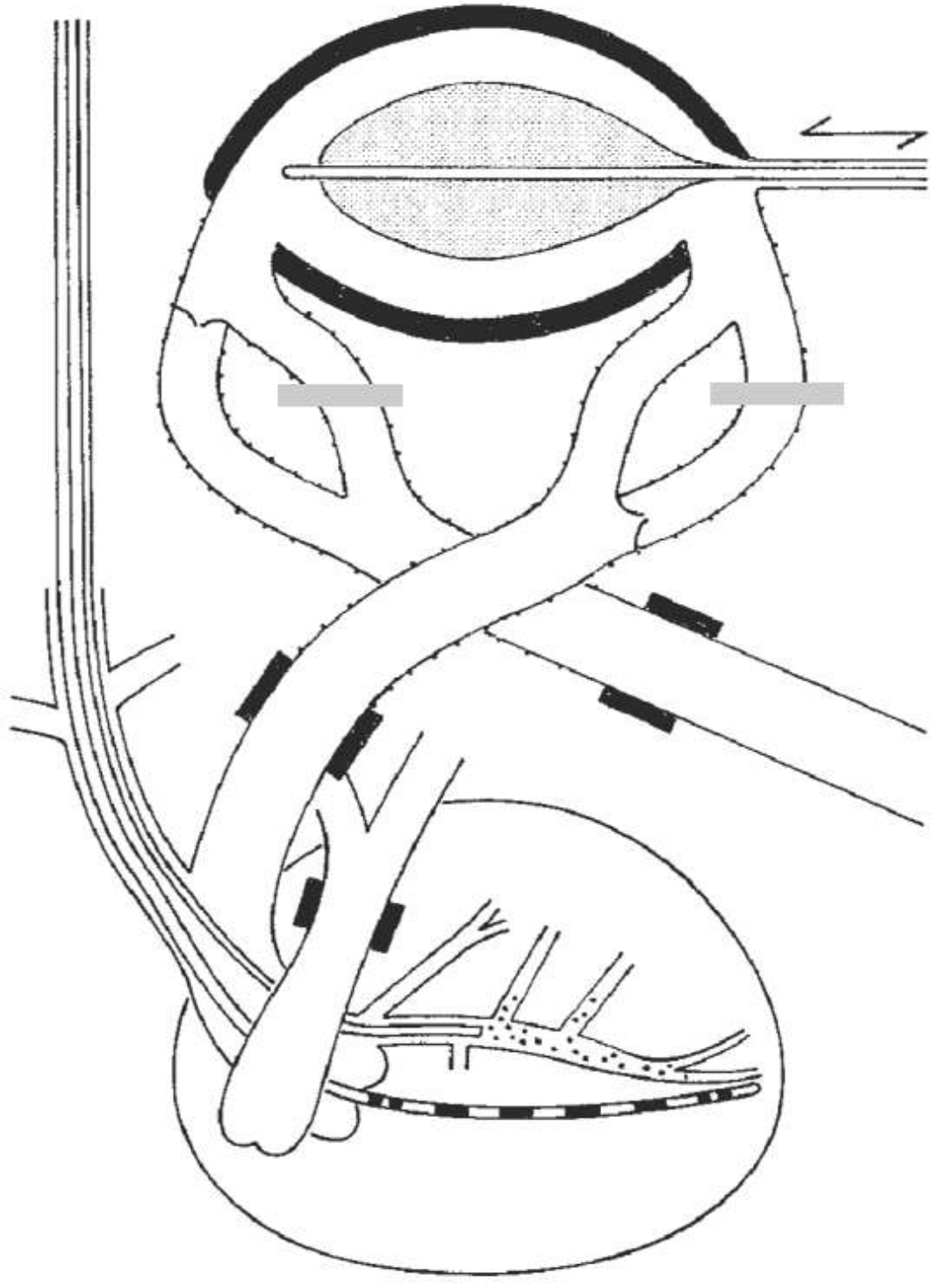

Figure 16. $\mathrm{BMH}$ model is made of a stiff polyurethane chamber with an integrated pumping balloon. The dividing and re-uniting vascular prostheses were connected end -to-end with the divided descending aorta. In this setting two of the four prosthetic limbs carried heart valves. Thus, by clamping, no, one or two valves could be integrated into the circulation. The influence of different valve configurations on circulation could be evaluated in supporting a failing heart. Ultrasonic flow probes were placed around the pulmonary artery, aortic arch and the descending aorta. Within the left heart ventricle a conductance catheter was placed, and via a catheter within the left coronary artery an embolization could be induced and a flow wire could be introduced [12]. 


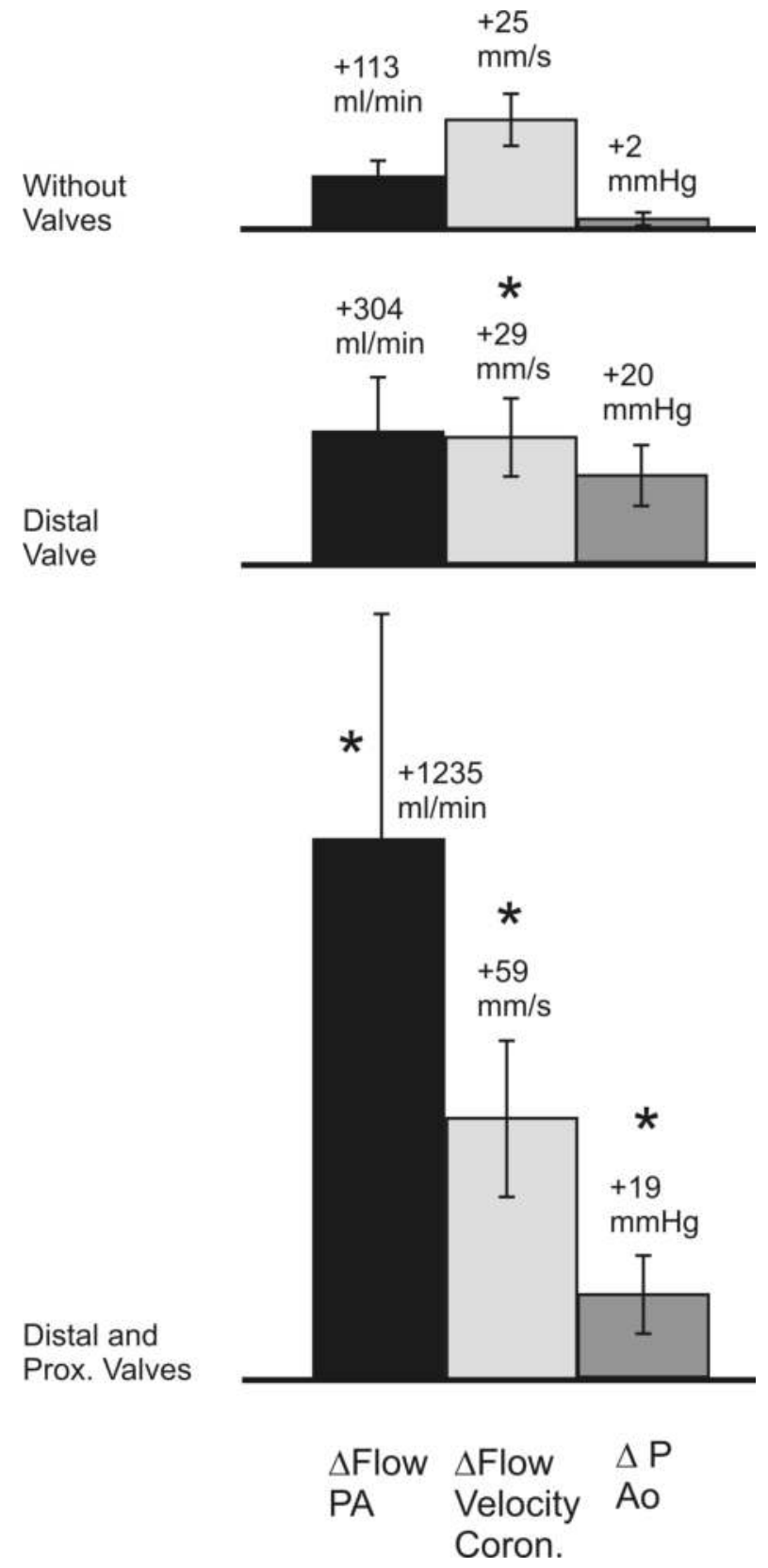

Figure 17. Results of the BMH model described in Fig. 16, without, with a distal and with two valves: mean aortic pressure $\left(\mathrm{P}_{\mathrm{Ao}}\right.$ grey column), mean pulmonary flow $\left(\mathrm{Q}_{\mathrm{PA}}\right.$, black column), mean flow velocity within the left coronary artery $\left(V_{c}\right.$, white column) [12]. 
Valve-less BMHs offered an additional pulmonary flow of $113 \pm 37 \mathrm{ml} / \mathrm{min}$ resp. $5.4 \pm 1.8 \%$, those with one distal valve offered $304 \pm 126 \mathrm{ml} / \mathrm{min}$ resp. $14.5 \pm 6 \%$. BMHs equipped with two valves increased the pulmonary blood flow by $1235 \pm 526 \mathrm{ml} / \mathrm{min}$ resp. $58 \pm 25 \%(\mathrm{p}<0.05)$, the mean aortic pressure in this setting raised to $19 \pm 9 \mathrm{mmHg}(\mathrm{p}<0.05)$ and the coronary flow velocity to $59 \pm 18 \mathrm{~mm} / \mathrm{sec}(\mathrm{p}<0.05)$. Corresponding reduction of left ventricle's end-diastolic pressure ranged from 31 to $17 \mathrm{mmHg}(\mathrm{p}<0.05)$, while the myocardial dp/dt increased by $470 \pm 192 \mathrm{mmHg} /$ s resp. $145 \pm 48 \%(\mathrm{p}<0.05)$.

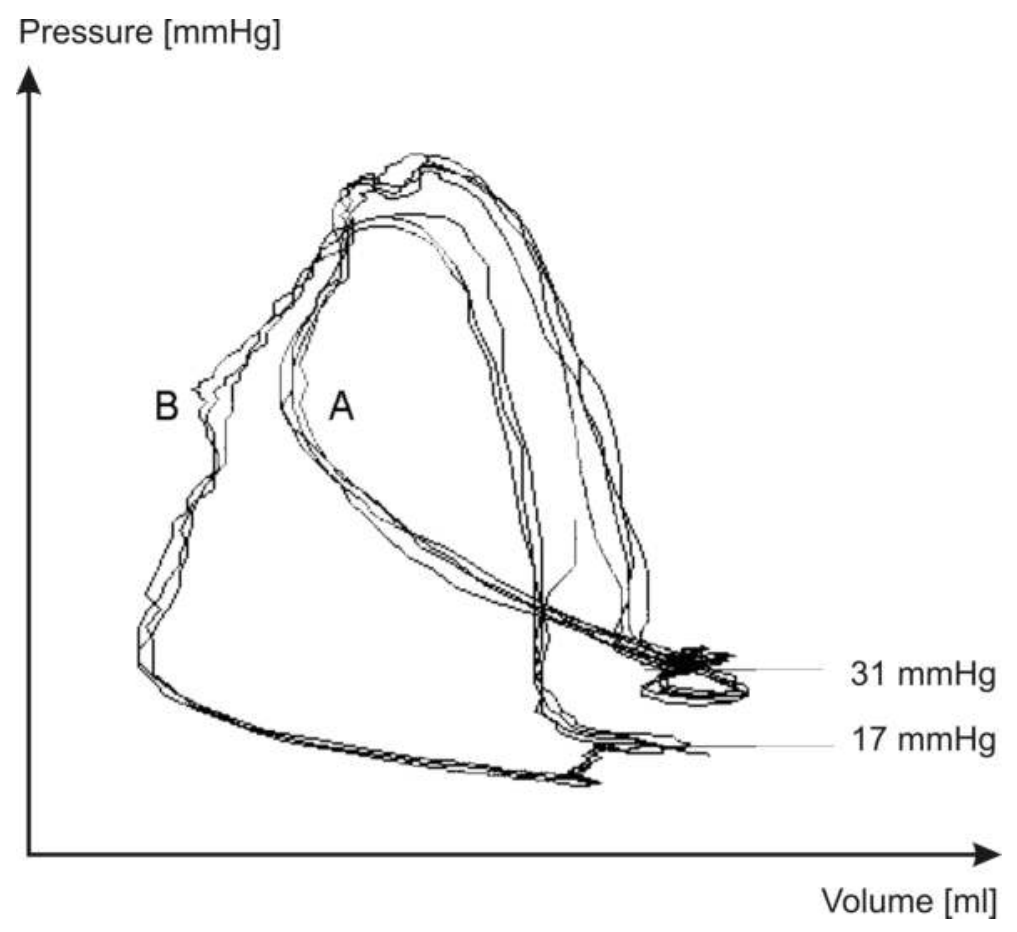

Figure 18. PV- loops from a conductance catheter placed in the left heart ventriclea cavum, without (A) and with an activated (B) double-valved BMH-model as shown in Figure16. It works ECG-triggered in a 1:2 mode with a balloon inflation of $60 \mathrm{ml}$ helium gas. The area within a loop represents the left heart ventricles stroke work. During activation of the $\mathrm{BMH}$-model the stroke work of the failing heart ventricle is increased (B) and the end-diastolic pressure (LVEDP) drops from 28 to $14 \mathrm{mmHg}[12]$.

The use of two valves in BMHs is essential for a relevant circulatory support. Unloading and contractility of the left heart ventricle were thus improved significantly. Two-valves-BMHs driven by a sufficient skeletal muscle ventricle may contribute to the therapy of a failing myocardium. 


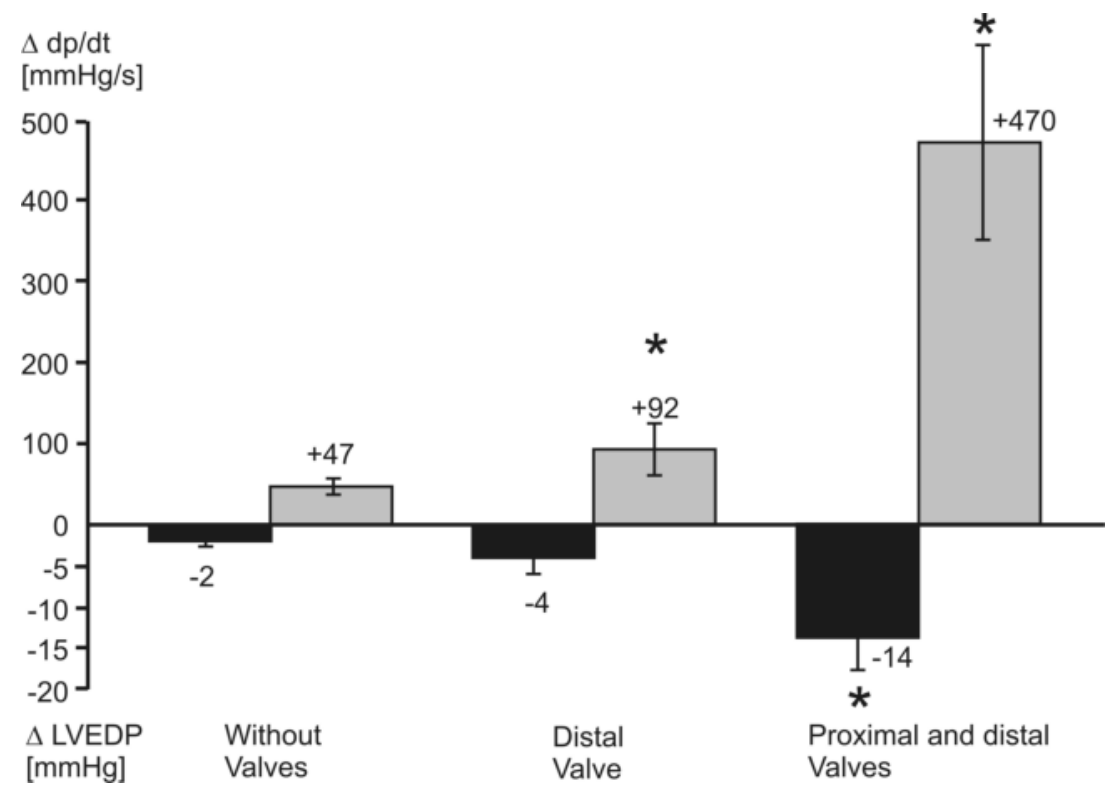

Figure 19. Reduction of the left ventricular end-diastolic pressure (LVEDP, black columns) evaluated as demonstrated in Figure 16 and 18 and an increase of the left ventricular contractility activation of the pumping balloon from the $\mathrm{BMH}$-model in Figure 16, without, with a distal and with a proximal and a distal valve.

\section{Valve equipped Biomechanical Hearts}

As demonstrated above, efficacy of BMHs on the circulation is dependent on the integration of two heart valve prostheses into the in- and outflow part of the pumping chamber. Valve equipped Biomechanical Hearts were constructed and integrated within circulation in adult Boer goat $(n=5)$, and pharmacological stimulation with the $\beta$-2-stimulator Clenbuterol. (5X150 $\mu \mathrm{g} / \mathrm{wk})$. This pumping chamber, made of PTFE, was anastomosed to the descending aorta by two ring armoured PTFE-prostheses (Impra Medica GmbH, München). Between these prostheses two porcine glutaraldehyde fixed valve bearing porcine aortic conduits were integrated like shown in Figure 20. 


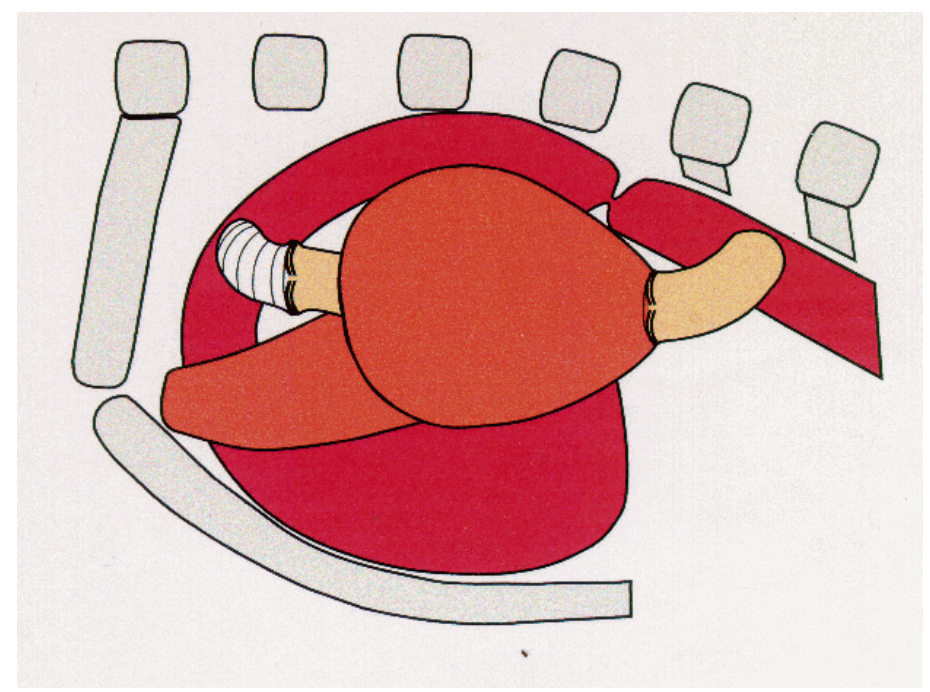

Figure 20. Scheme of an experimental setting from a valve equipped Biomechanical Heart in a big animal model (Boer goats) in an aorto-aortic configuration. The thoracic aorta is ligated between the two anastomoses. Two porcine glutaraldehyde fixed valve bearing porcine aortic conduits were integrated between the connecting PTFE prostheses and the PTFE pump ventricle.

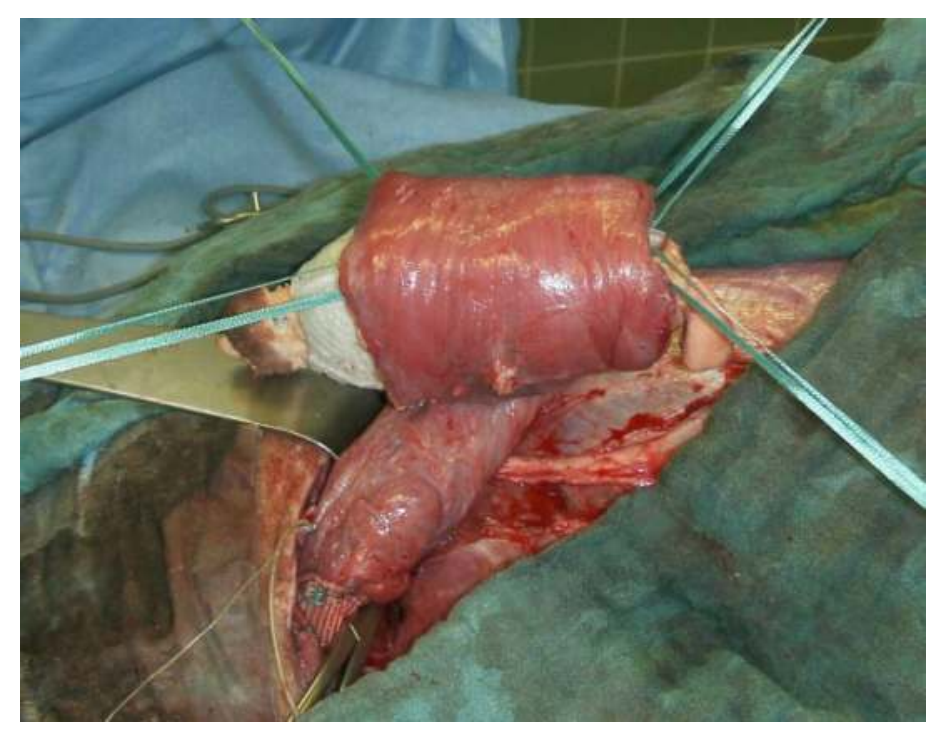

Figure 21. Operative situs of a BMH before transferring it into the cavity of the thorax, with four strings to fix it via the thoracic wall to the inner thoracic surface. Two stimulation electrodes and an artificial muscle tendon made of Dacron for a re-fixation onto the external thoracic wall are visible. 

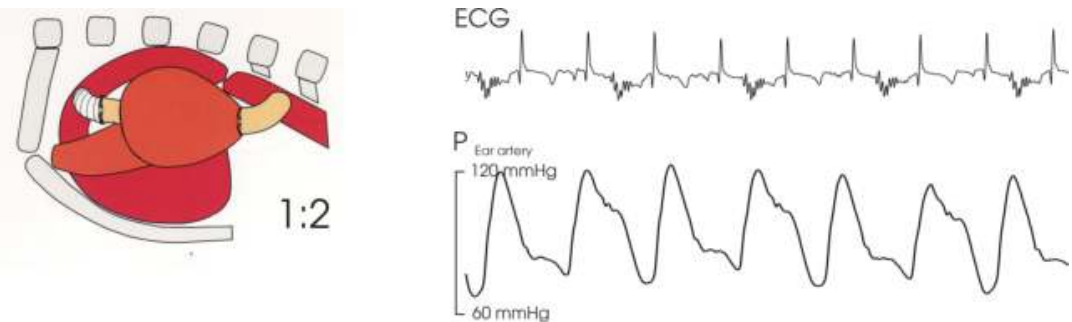

Intraoperative pumping capacity of a $\mathrm{BMH}$ additional to a healthy heart with $1029 \mathrm{ml} / \mathrm{min}$ in a $1: 2$ mode.

Stimulation pattern:

$5 \mathrm{~V}, 6$ pulses, $33 \mathrm{~Hz}, 240$ us pulse width 235 ms R-Deloy

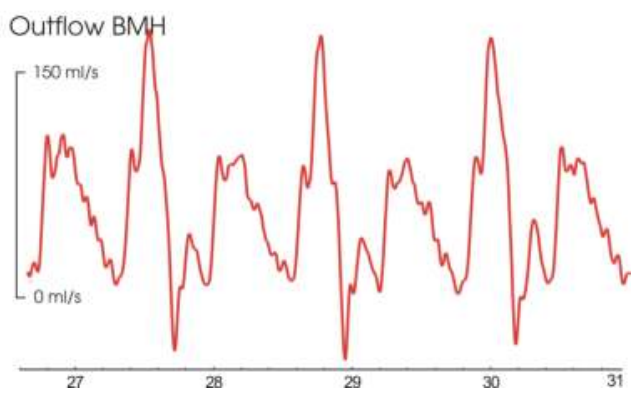

Figure 22. Intraoperative testing of the function of a valve equipped BMH by visualization of burst stimulation within the ECG, a 1:2 support within the arterial pressure curve and the flow curve which was obtained by a flow probe around the distal biologic aortic conduit

\begin{tabular}{|c|c|c|c|c|c|c|}
\hline & $\begin{array}{l}\text { Stroke } \\
\text { Volume (L/ } \\
\text { min) }\end{array}$ & $\begin{array}{l}\text { Type of } \\
\text { pumping } \\
\text { chamber }\end{array}$ & $\begin{array}{l}\text { Days of } \\
\text { Pumping }\end{array}$ & $\begin{array}{l}\text { Days of } \\
\text { Survival }\end{array}$ & MHC-I & $\begin{array}{l}\text { Significant Findings and Cause } \\
\text { of Death }\end{array}$ \\
\hline Larry & 1029,6 & Dacron & 93 & 93 & $56 \%$ & Seroma in both pleura \\
\hline Juan & 407,5 & Dacron & 267 & 301 & $95 \%$ & $\begin{array}{l}\text { Acute abdomen, total thrombosis } \\
\text { of the pumping chamber, } \\
\text { sacrification }\end{array}$ \\
\hline Ugo & 444,5 & Dacron & 136 & 182 & $78 \%$ & $\begin{array}{l}\text { Acute abdomen, total thrombosis } \\
\text { of the pumping chamber, } \\
\text { sacrification }\end{array}$ \\
\hline Stanley & 474,9 & $\begin{array}{l}\text { ePTFE } \\
\text { (titanized) }\end{array}$ & 225 & 385 & $94 \%$ & $\begin{array}{l}\text { Hematothorax, bleeding from } \\
\text { proximal conduit, no chamber } \\
\text { thrombus formation }\end{array}$ \\
\hline Pierre & 588 & $\begin{array}{l}\text { ePTFE } \\
\text { (titanized) }\end{array}$ & 180 & 446 & $100 \%$ & $\begin{array}{l}\text { Acute abdomen, intestinal } \\
\text { infection, no chamber thrombus } \\
\text { formation }\end{array}$ \\
\hline Valeri & 576,3 & $\begin{array}{l}\text { ePTFE } \\
\text { (titanized) }\end{array}$ & 531 & 914 & -- & $\begin{array}{l}\text { Infection, sepsis. no chamber } \\
\text { thrombus formation }\end{array}$ \\
\hline
\end{tabular}

Table 1. Intra- and post-operative data of six experimental valve equipped BMHs in adult Boer Goats 


\section{Self-endothelializing titanized blood contacting surface for Biomechanical Hearts}

Titanium has proven itself as the leading structured metallic biomaterial for 50 years [13]. One reason for this widespread use is the excellent biocompatibility of the metal and its alloys [14]. Theoretically, surface coating of the blood contacting PTFE may open new avenues for improving biocompatibility of this kind of implant material. However, a titanium coating on PTFE seemed not to be possible until now due to the high temperatures needed for commonly used sputtering techniques. Therefore a novel coating method was used [15] for PTFE applying a plasma activated chemical gas deposition (PACVD) at temperatures of $30-35^{\circ} \mathrm{C}$.

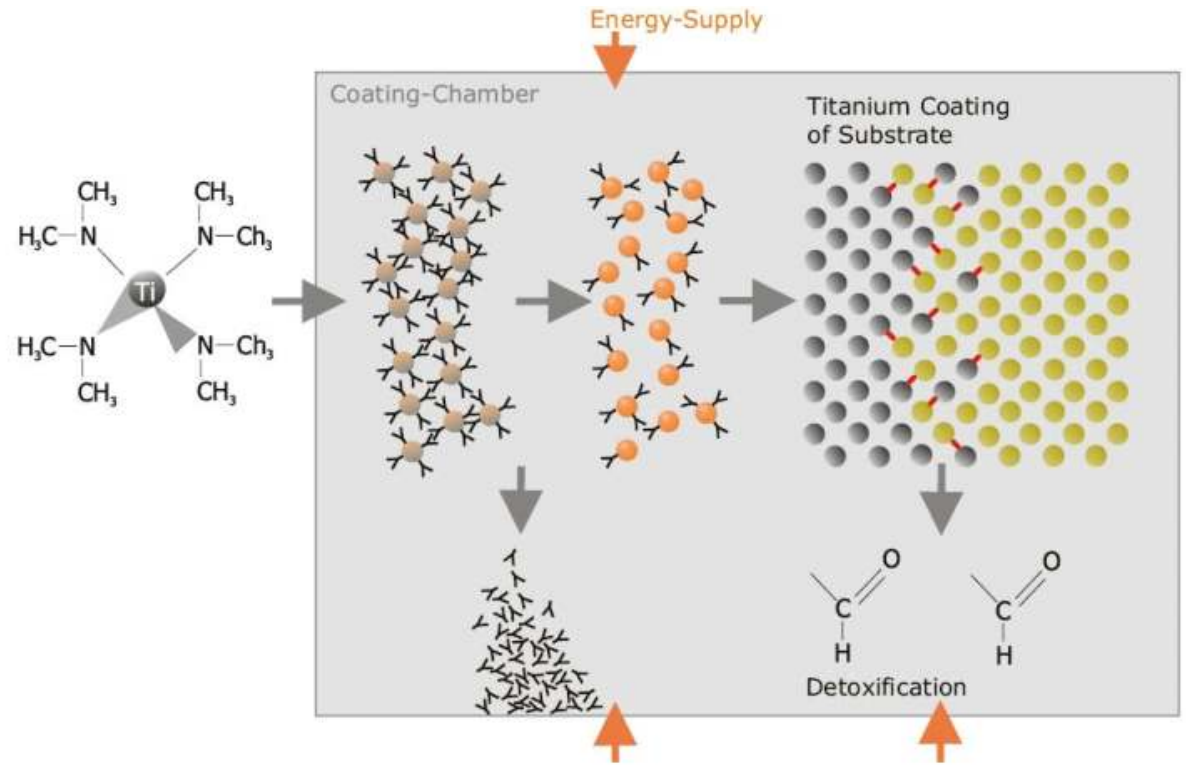

Figure 23. Principle of titanium coating at low temperature (see text).

PACVD is a coating technology (Pfm Titanium GmbH, Nürnberg, Germany, patent number EP 0897997 A1) where the so called precursor (Tetrakisdimethylamidotitanium, Ti $\left.\left[\mathrm{N}\left(\mathrm{CH}_{3}\right)_{2}\right]_{4}\right)$ is transferred into the gas phase and brought into the reactor by a carrier gas like nitrogen gas [16]. The plasma is able to supply the substrate with high energy while the temperature during deposition can be kept low at about $30-35^{\circ} \mathrm{C}$. Within that non-thermal plasma with high electron temperatures but neutrons and ions at room temperature, solely the electrons can follow a quickly changing electrical field with a typical frequency of 13.56 $\mathrm{MHz}$ under low pressure plasma as described in detail elsewhere [17]. The precursor, or part of it, reacts with the substrate and creates a layer of 30nm in thickness (Figure 23). 
The blood contacting surface of the PTFE-made pumping chamber was titanized as described above. This titan surface attracts progenitor cells derived from the bone marrow which were delivered into circulation. The seeded cells transform into endothelial cells within time [18]. This kind of self-tissue engineering of the blood contacting surface is mandatory to prevent thrombo-embolism mainly for blood pumps contracting on demand [14].
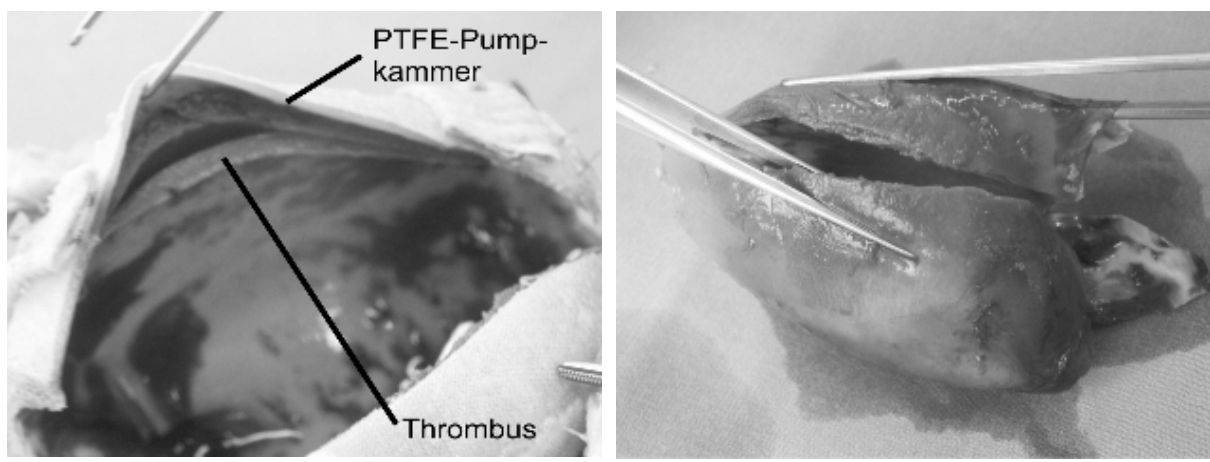

Figure 24. Thrombosis of the total blood contacting surface 8 weeks after implantation (left): Isolated thrombus formation from the PTFE- pumping chamber (right).
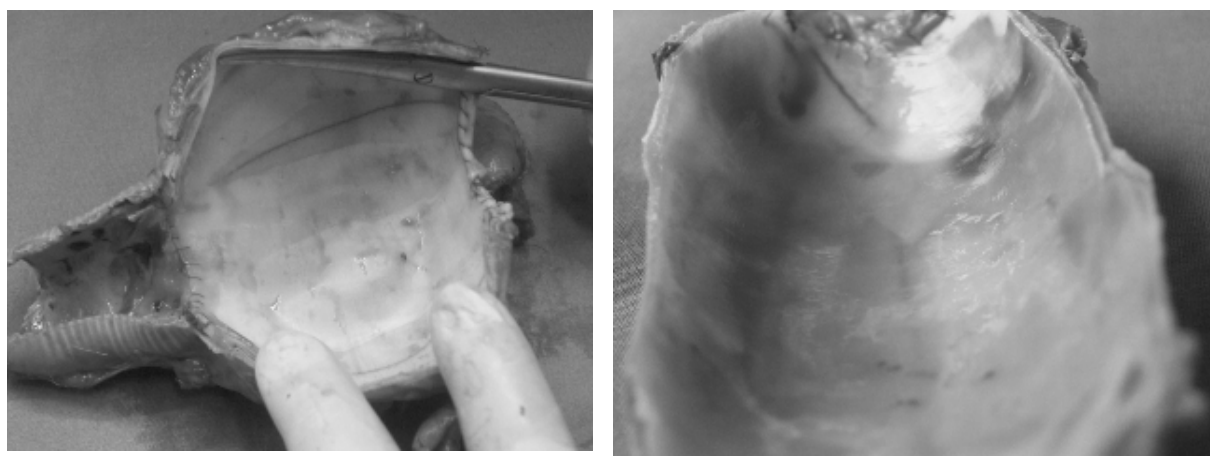

Figure 25. Titanized PTFE pumping chamber 6.5 months after implantation without any thrombus formation. This thin cover could be identified as an endothelial layer by a von Willebrand immun-histological staining. 


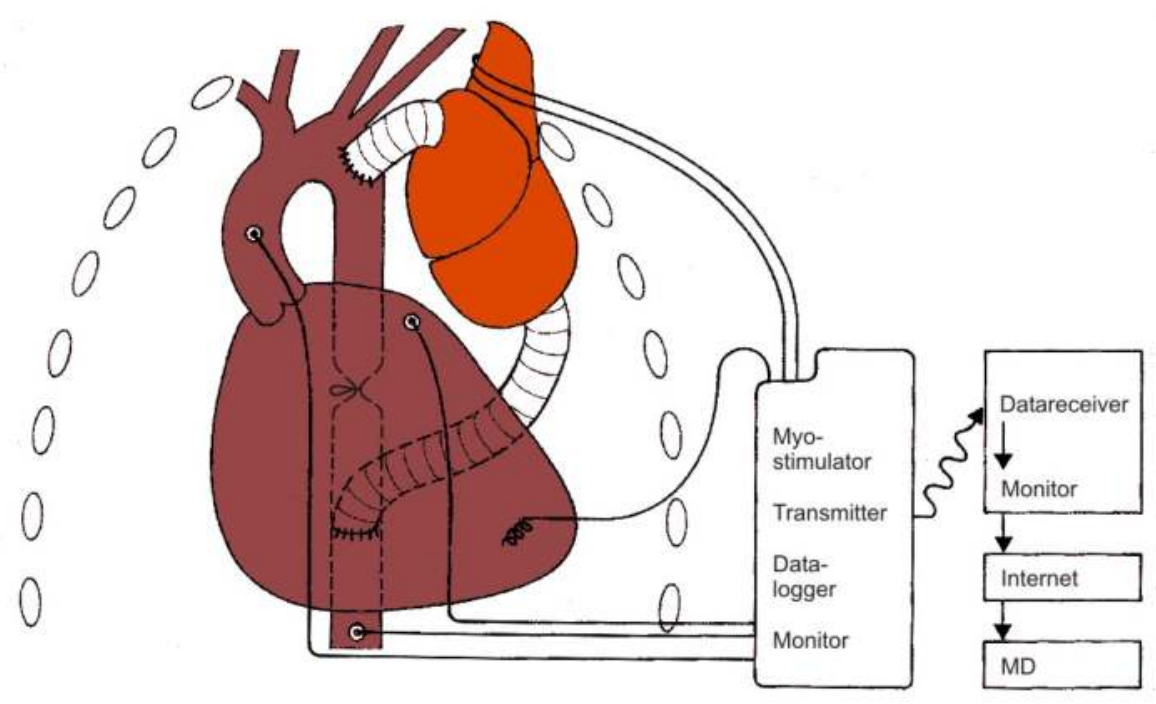

Figure 26. Clinical setting of a BMH in an aorto-aortic configuration

\section{Summary and perspectives}

$\mathrm{A} \mathrm{BMH}$ is therapeutically indicated for patients with end-stage heart failure with an additional need of a support with 2-3 litres per minute "on demand", especially for candidates older than 60 years having no chance for heart transplantation. For a severe bi-ventricular myocardial insufficiency however, heart transplantation is the first choice.

Experimental Biomechanical Hearts in Boer goats with autologous skeletal muscle were to construct pumping up to $1.400 \mathrm{~mL} / \mathrm{min}$ for more than 400 days under support of Clenbuterol. Furthermore was to demonstrate that a BMH model supporting a failing heart in Boer goats could pump about 2 litre blood per minute additionally. BMHs equipped with two valves were most effective in-vivo. Effective circulatory support by counter pulsation was achieved by SMVs elsewhere [19].

Muscle damage and power-loss of a BMH can be avoided by a muscle protective myostimulator applying a closed-loop controlled stimulation and thus maintaining type IIa fibres over years (Microstim $\mathrm{GmbH}$, MyoSen ${ }^{\circledR}$, Wismar; Germany). A titanized blood contacting surface with endothelialization (Pfm titanium $\mathrm{GmbH}$, Nürnberg; Germany) might prevent thromboembolic complications. In the light of 25 years of systematic progress in basic science of muscle powered cardiac assist this biologic treatment option should become reconsidered as a future surgical treatment option for the therapy of end-stage heart failure [20]. 


\section{Acknowledgements}

We thank Prof. Dr. Petra Margaritoff, Hamburg University of Applied Sciences, Germany for critical reading of the manuscript.

\section{Author details}

Norbert W. Guldner ${ }^{1}$, Peter Klapproth ${ }^{2}$, Hangörg Zimmermann ${ }^{3}$ and Hans- H. Sievers ${ }^{1}$

*Address all correspondence to: Guldner@uni-luebeck.de

1 Clinic of Cardiac Surgery, University of Lübeck, Germany

2 Microstim GmbH, Wismar, Germany

3 Pfm Titan GmbH Nürnberg, Hangörg Zimmermann, Germany

\section{References}

[1] Acker MA, Hammond RL, Mannion JD, Salmons S, Stephenson LW. Skeletal muscle as the potential power source for a cardiovascular pump: assessment in vivo Science 236 (1987), 324-327.

[2] Bridges Jr. CR, Brown WE, Hammond RL, Anderson DR, Anderson WA, DiMeo F, Stephenson LW. Skeletal muscle ventricles: Improved performance at physiologic preloads . Surgery 106 (1989), 275-28.

[3] Hooper TL, Niinami H, Hammond RL, Lu H, Ruggiero R, Pochettino A, Stephenson LW. Skeletal muscle ventricles as left atrial-aortic pumps: short-term studies . Ann Thorac Surg 1992;54:316-322.

[4] Lu H, Fietsam R, Jr., Hammond RL, Nakajima H, Mocek FW, Thomas GA, Ruggiero R, Colson M, Stephenson LW. Skeletal muscle ventricles: left ventricular apex to aorta configuration. Ann Thorac Surg 1993;55:78-85.

[5] Thomas GA, Hammond RL, Greer K. Functional assessment of skeletal muscle ventricles after pumping for up to four years in circulation. Ann Thorac Surg 2000; 70 (4): 1281-1289.

[6] Guldner NW, Eichstaedt HC, Klapproth P, Tilmans MHJ, Thuaudet S, Umbrain V, Ruck K, Wyffels E, Bruyland M, Sigmund M, Messmer BJ, Bardos P. Dynamic training of skeletal muscle ventricles. A method to increase muscular power for cardiac assistance. Circulation 89 (3):1032-1040 (1994). 
[7] Klapproth P, Guldner NW, Sievers HH. Stroke volume validation and energy evaluation for the dynamic training of skeletal muscle ventricles. Int.J Artif Organs 1997; 20:313-21.

[8] Guldner NW, Klapproth P, Großherr M, Rumpel E, Noel R, Sievers HH. Clenbuterol supported Dynamic Training of Skeletal Muscle Ventricles Against Systemic Load- A Key for Powerful Circulatory Assist? Circulation 101:2213-2219 (2000)

[9] Sharif Z, Hammond RL, Mc Donald P, Vander Heide R, Stephenson LW. The functional and histological effects of clenbuterol on the canine skeletal muscle ventricle. J Surg Res. 123, 89-95 (2005)

[10] Lopez-Guajardo A, Sutherland H, Jarvis JC, Salmons S. Induction of a fatigue-resistant phenotype in rabbit fast muscle by small daily amounts of stimulation. J Appl Physiol. 2001; 90 (5):1909-18

[11] Guldner NW, Klapproth P, Großherr M., Rumpel E, Noel R, Sievers HH. Biomechanical Hearts: Muscular Blood Pumps, Performed in a One-Step Operation, and Trained under Support of Clenbuterol, Circulation 2001;104 717-22.

[12] Guldner NW, Klapproth P, Margaritoff PRJ, Noel R, Sievers HH, Großherr M. The Impact of Valves in a Biomechanical Heart Model Assisting Failing Hearts. Asian Cardiovasc Thorac Ann 2009;17:1-6

[13] Sivaram S. Chemical vapor deposition: thermal and plasma deposition of electronic materials.Van Nostrand Reinhold, New York. 1995.

[14] Dag B. (Ed.) Surface Characterization.Wiley-VCH, Weinheim. 1997.

[15] Guldner NW, Jasmund I, Zimmermann H, Heinlein M, Girndt B, Meier V, Flüß F, Rohde D, Gebert A, Sievers HH. Detoxification and Endothelialization of Glutaraldehyde-Fixed Bovine Pericardium With Titanium Coating; Circulation; 2009;119:1653-1660

[16] Brunette DM. Titanium in medicine. Springer, Berlin, Germany. 2001.

[17] Sedelnikov N, Cikirikicioglu M, Osorio-Da Cruz S, Khabiri E, Donmez Antal A, Tille JC, Karaca S, Hess OM, Kalangos A, Walpoth B. Titanium coating improves neo-endothelialisation of ePTFE grafts. Thorac Cardiovasc Surg. 2006; 54 suppl 1: 83-115.

[18] Guldner NW, Jasmund I, Zimmermann H, Heinlein M, Girndt B, Großherr M, Klinger A,Sievers HH. The First Self-Endothelialized Titanium Coated GlutaraldehydeFixed Heart Valve Prosthesis within Systemic Circulation.J Thorac Cardiovasc Surg 2009, 138: 248-25

[19] Ramnarine IR, Capoccia M, Ashley Z, Sutherland H, Salmons S, Jarvis JC. Counterpulsation From the Skeletal Muscle Ventricle and the Intraaortic Ballon Pump in the Normal and Failing Circulations. Circulation. 114 [suppl I]: 1-15 (2006)

[20] Salmons S. Cardiac assistance from skeletal muscle: a reappraisal. Europ J of Cardio thoracic Surg 35, 204-213 (2009) 